\title{
Urban fabric and individual behavior: the effect of urban fabric development on the privacy of individual behavior - Koya city as a case study
}

\author{
H. A. Hussein \\ Department of Architectural Engineering, Koya University, \\ Kurdistan Region, Iraq
}

\begin{abstract}
Seeking for a shelter is Man's main request since his existence on earth; security and privacy were his demands for this shelter; no matter how simple or complicated it was. Islam paid a great deal of attention to privacy in every building act, as this privacy might be a suitable cure for a lot of social issues. This paper, therefore, discusses the main characteristics of the social system and traditions, in an Islamic society, which has been reflected in its traditional home. In the mean time, the home itself might possibly affect the social behavior of the resident with its spatial organization and the relationship between the inside and outside, so the privacy level may vary according to these relationships between the inside-inside spaces and the inside-outside spaces.
\end{abstract}

Keywords: urban development, spatial behavior, privacy, Koya, Kurdistan.

\section{Introduction}

Generally, privacy indicates the differentiation of something from the whole or common things. In many studies privacy used to be related to individuality, subjectivity, and identity. In architecture, the term privacy has many deferent definitions, but they all refer to that situation when Man has the ability to occupy his own space that he doesn't share with others. Rapoport was one the most important researchers whom studied privacy in deferent kinds of environments and societies, he found that local interest in privacy varies according to the type of environment, people, and time; he also emphasized the threshold of isolation 
for individuals, families, and societies; while Helson related the right level of privacy with the demographic density and its variety from one environment to another. Conversely, "reducing the stimulus" theory assures that Man; regardless of the social background or the demographic density, he'll try to have all the privacy he can get and that would affect his preferred level of privacy.

\section{The need for privacy}

Man's need for being isolated from others for a little or long period of time due to certain conditions, in order to keep his life going and stable within his environment; is one of Man's biological needs, which varies from one to another, and from one society to another. During their study to the impact of buildings on human behavior, many psychologists and sociologists focused on the main role of the visual privacy of the built environment; some refers to the privacy as a general requirement that helps fulfilling human needs such as security, belonging, and achieving self-esteem; while others focused on the cultural impacts on spatial behavior considering that the value of the place is a result of being in, and the notion of place is related to the separation of inside and outside.

\subsection{Entrance}

The entrance is considered as one of the main contact and circulation elements in the building, as its location affects the full planning of the building and its various units layout. To avoid exposing entrance's door when it is opened which allows the inside to be exposed to the strangers in the outside; the plan of the traditional house had became with a shifted axis entrance, so the door of the main entrance won't be in the same line with the courtyard door. Therefore, it is required to take care of the design of entrance in order to keep privacy; as the residents of the house should be inward oriented while the guests have an opposite orientation to grant house's privacy; both orientations would meet in an in-between zone that would be added either to the first one to be used by the residents, or to the second to be used by the guests. Muslim designer also considers external openings and the external architectural elements; in contrary of the contemporary architecture where most of the openings doesn't meet Muslim's requirements, Muslim designer considers buildings' heights as well, to prevent visual access to the roof, therefore, he used parapets (no less than $1.75 \mathrm{~m}$ height). The threshold concept is related to the social joints. These joints start with the relationship between house and street. In the old crowded neighborhoods, there's usually a strong relationship between house and street's facilities. As a result of having the street as a space that expresses belonging and privacy, contrary to contemporary streets, which were designed merely as paths for circulation. Hillier considered the borders between inside/outside as controlling barriers of the internal space, and those whom outside of them are strangers, who might turn into guests when using the entrance. Entrance, 
therefore, is considered as the means of determining resident ID and turning_a stranger into a guest.

\subsection{Behavior}

For contemporary psychologists, behavior refers to all the acts that a living creature do according to its previous experiences, whether they were common among the creatures of the same type, or individual that belongs to someone specific. Behavior includes the physical and perceptional type of acts, though some behaviorists use this term for physical acts exclusively. Behavior is a dynamic process that involves both Man and his environment, as he has a negative/positive impact on it, and it has the same on him. Spatial behavior varies among different societies in the world, and among the people from the same society as well, according to cultural and social background; this is why it's a wrong guess to think that all the residential units are used in the same way, or that all the residents have the same design requirements; as space occupation, and individuals behavior, would affect the form of space and its furniture layout, they also affect elements' orientation and environmental control of them. Neglecting these requirements would result an uncomfortable built environment. Behavior, for sociologists, includes all the acts and activities that Man does as a result of his inner motivations; while architects detect physical behavior to understand people's way of using and occupying spaces in addition to their motivations beyond that. Spatial behavior is a measurable phenomenon in contrary of the perceptional type of acts which are hard to be measured accurately. Man's behavior could indicate his subjective motivations, his spatial environmental properties, his schemata and mental images of his world; and his interpretation to their significations. By this way one can differentiate between an environment that offers enough opportunities for behavioral options, and another one that imposes certain kinds of behavior. Behavior, as a result of this vital interaction between Man and his environment, is, therefore, related to urban features as part of the environment, and as a stimulus that motivate Man.

\subsection{Sensing security}

Fulfilling the human need to be secure and satisfied is very important, and could be insured by increasing spatial enclosure with having a clear definition and borders of the space, so it could give a feeling of enclosure that is related to the human scale. Security is the protection against everything that bothers Man whether it was a weather change or a noise or each what pollute the environment.

\subsection{Unity}

One of the space characteristics is the unity of composition, as it refers to integration and harmony of a composition. It could be reached by dominance i.e. preferring a certain element or an important building over others gives the impression of space unity, unity could also be achieved by using a certain style, 
or repeating an element that connect deferent buildings. Thinking is still the main power that could achieve unity of buildings with a concept.

\section{The relationship between mass and space}

There should be a harmony between mass and space when designing an urban place; therefore, it is necessary to care about the shape of space just as we care about the form of the mass considering that one of them formulates the other. Putting a solid mass in an open space would orientate the mass to the outside, while the space around it would border it, so the mass would be the most important one, while there would be no clear definition for the space itself, that's what we used to experience in contemporary cities as a result of the modern architecture trend. On the other hand, when buildings surround the space, then the space would be easily realized and conceived, and whenever these buildings are closer to each other, the space becomes with higher enclosure, and more identified; as this enclosure depends on the ratio between the height of surrounding buildings and the span between them; and that's one of the Islamic cities virtues, with this way urban spaces would compose open rooms in the fresh air to enclose various activities within the spatial structure of the city. There are various ways of treating urban spaces, the relationship between mass and space, and formulating space.
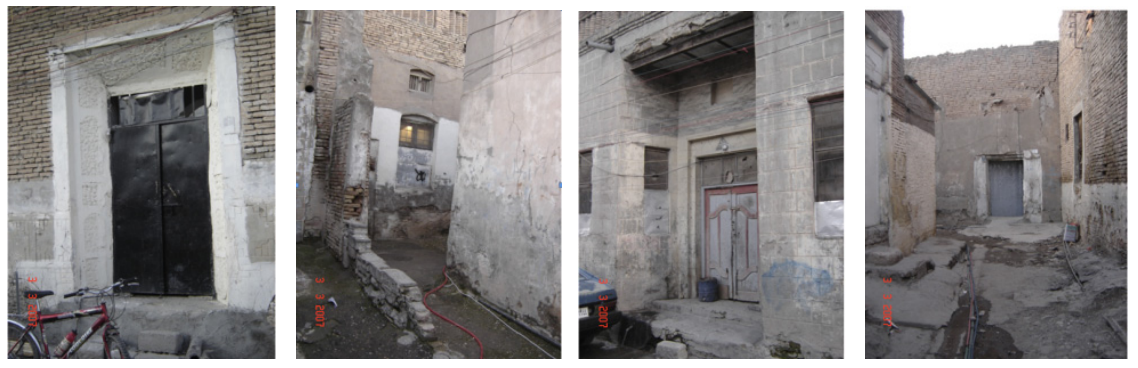

Figure 1: $\quad$ Types of entrances in the ancient urban fabric, taking into account privacy and non-optical breakout.

\subsection{Buildings within a space}

Several impressions could be resulted from locating buildings within urban spaces and their relationship with the main circulation path. During the 19th century, it was common to see a building mass occupying the location that is surrounded by streets to be a part of the street's urban façade, and the inner courtyard would be a public space within a building as well as providing natural lighting and ventilation; so the whole composition would form a 3D mass; in such case Street's façade would seem divided into several split facades which are separated via wide spaces in-between, that would weaken the sense of unity and continuity. Sometimes an important building could be focused on, by changing 
street direction or making it stand out of a line of its neighboring buildings' facades, so it becomes a land mark; and when separating a building from the others and creating open spaces in front of each of its four facades, it would be easier to realize its mass and treat those spaces as public spaces within city's structure, but this will affect the role of the courtyards as public spaces. In assembled individual buildings that are connected with orthogonal geometrical relationships, the horizontal lines would end to three common points that would connect those buildings together within the space, rather than bordering and identifying space, such configuration requires an open location so the viewer could enjoy buildings' geometrical configuration, but will disconnect city's structure, as in our contemporary cities.

\subsection{Buildings around the space}

Connections among buildings would contribute creating spaces with various psychological and visual impacts. By arranging buildings around the space, the impact of their size would be clearer and the space would be more identified. Whenever the joints (spans) between those buildings around the space would decrease, sensing space's enclosure would increase. There are some spatial configurations commonly seen in those gridiron-roads' cities, where the buildings surround an open block, while streets separate space's edges from its
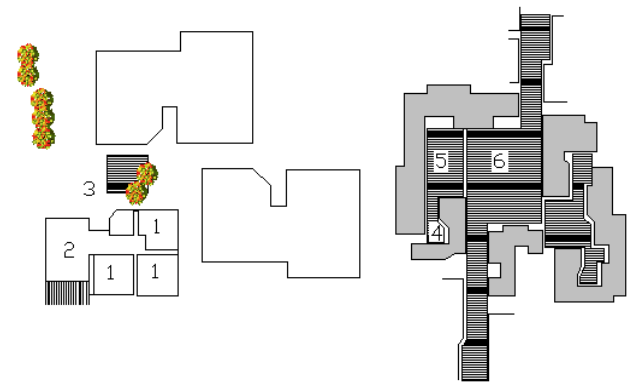

1-Lowest space: a chamber space.

2-Dwelling space: courtyard or family living room.

3-Cluster, court.

4-Mini neighborhood.

5-Neighborhood.

6-Residential district.

These spaces vary in terms of size, shape, area, dimensions, function, privacy, etc. And this hierarchy of spaces gives the city a clear and distinctive organic fabric because of the spatial hierarchy link with the organic fabric of the city.

Figure 2: Grading in the spaces with the private grading. 
floor, and the open corners decrease space's enclosure. However, if the visual access for these corners is prevented or decreased, the sensing of space's enclosure, borders, and identification would be increased. Visual access could be prevented by a sculpture, for example that is located in the middle of the space, but if there are three accesses for the space and there's a visual access from two of them, then locating the building in front of the third access would enclose the spatial configuration and had the dominance, so on, the use of courtyard was developed in the contemporary spatial configurations by surrounding space with buildings, and that's a virtue of Islamic cities.

\subsection{Buildings with various heights}

One can sense order and unity within space when the buildings are with the same height, or with some harmonic treatments (in design, materials, or color, etc.); but, when the heights of buildings varies, then they will lose their visual continuity unless those buildings are unified by a linking element that could give them a visual unity. As high buildings define their location within the space rather than defining the space, so in order to make the linking element more efficient in connecting these buildings, it should be related to Man's visual angles, so he would be aware and related visually to that linking element which could be as example an arcade or a group of low buildings with similar heights, without such linking element there would be only a non connected group of spread out buildings that disconnect the urban fabric and give local citizens the lack of belonging.

\section{Field study}

Studying the ancient and modern urban fabric of two districts in Koya, through the study of factors affecting the privacy of individual behavior:

1. Circulation and street space

2. Building heights

3. Services

4. Property

5. Population density

6. Architectural Conservation

7. Building materials that used in the maintenance

8. House patterns

9. Shifted axis entrances to prevent visual access from outside to inside in order to assure privacy

10. Standard of quality of life.

Due to the large number of influencing factors, this paper will make the comparison between these two districts according to only three of them as follows: 


\subsection{Circulation and street space}

Circulation systems are considered as a main demand for each part of the city, as the space will lose its value when it loses its access for exchanging information and purposes. Street is defined as the linear plane that circulation acts happened all over its length and among the buildings that compose it. It links deferent sites with each other and is used by pedestrians and cars. In the old urban fabric, the paths and streets, in general, are narrow and winding, the main big streets are with minor branches on both sides, some of them are close-ended; those branches are too narrow that they hardly have enough width for one car or even less sometimes, while the main streets could have enough width for two cars. The winding streets; which are dynamic with a continuous change in viewing the facades of the compacted buildings, provide a high sense of enclosure, privacy, and isolation for the space and its surrounding buildings. This kind of streets affects positively on keeping privacy and strengthening social relationships. There are also external spaces that are located in the paths network's intersections, and those have many shapes and are considered as landmarks. This way is suitable for creating open external spaces that work as a natural entertainment to enhance the urban scene. The streets of the old urban fabric are considered as parts of the residential units, as there is a strong relationship between the street and the residential unit, as the street here is not a mere path, but also expresses belonging and privacy. On the other hand, the contemporary urban fabric with the wide orthogonal streets has no such relationship as those streets are no more than circulation paths.

\subsection{Building heights}

Various impressions are created in residents' minds by the relationship between buildings and the main circulation in the old urban fabric. In the old urban fabric, the heights of buildings are unified with a high enclosure ratio (building height /street width) which creates a shaded environment that is suitable for pedestrians. The residential units' types in this fabric are built in a way that the private spaces are started with the external wall of each, which would prevent exceeding over the others, and prevent visual access, unlike the contemporary urban fabric.

\subsection{Shifted axis entrances to prevent the visual access from outside to inside in order to assure privacy}

Old urban fabric, in spite of the narrow width of its paths, has the virtue of keeping privacy and preventing visual access by locating the entrances of the residential units in a way that they won't be in front of each other; and to enhance this privacy, most of these entrances are built as holes within the main wall, as the privacy of the house depends on the design of entrance and how to keep the internal space out of the outsiders visual access; in contrary of the contemporary architecture, where the openings don't provide such privacy. 

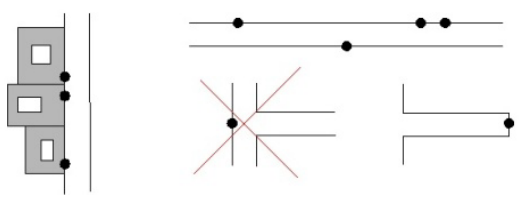

The door positions of house entrances

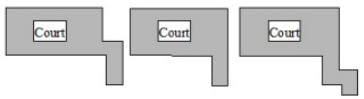

Houses indirect entrances

Figure 3: $\quad$ Entrance and door positions [5].

\section{Conclusion and recommendations}

- The recent regulations for planning the city are imported and not compatible with our society needs that require a study for local requirements and having new regulations.

- The plans that are submitted for the purpose of obtaining construction license must be controlled, as well as during implementation so as to prevent disturbing the privacy of others.

- Studying and protecting the old urban fabric will offer a clear local character.

- The urban fabric affects the privacy of the individual behavior.

- Deterioration and misuse of most of open spaces in the contemporary urban fabric need a study for the open spaces and their treatments.

- To achieve optimum local environment, users' behavior must be considered.

- Studying the old urban fabric characteristics to find solutions for the recent challenges that affected negatively on residents' privacy and behavior.

\section{References}

[1] Al-Azzawi, Hisham Adnan Aboud, 1998, The impact of intellectual structure change in the form of the urban fabric, $\mathrm{PhD}$, Faculty of Engineering, University of Baghdad.

[2] Qara Daghi, Amjad Mohammed Ali, 2004, The impact of changing the position of the optical penetration on urban infrastructure and architecture of the Islamic city, Ph.D., Higher Institute of Urban and Regional Planning, University of Baghdad.

[3] Tai, Ayad of Saddam Cltag, 1999, Fixed and Variable in the Islamic city, Master, Mrkzaltaktit Urban and Regional Graduate Studies, University of Baghdad.

[4] Al Nuaimi, Adel Hassan Jassim, 1999, The impact of the social behavior of Muslims in the formation of the residential environment within the Arab and Islamic city, Master, urban Mrkzaltaktit and Regional Graduate Studies, University of Baghdad. 
[5] Said, Raz Said Faraj, 2005, Attractions visual catalyst to do shopping, Master Thesis, Department of Architecture, University of Technology.

[6] Munshid, Abdalrozk Zamel, 2005, Meet Surfaces in Residential Buildings, Master Thesis, Department of Architecture, University of Technology.

[7] Rapoport, Amos, 1977, (Human Aspects of Urban form). 